\title{
The politics of redistribution
}

\author{
RUDOLF KLEIN
}

There are two, opposing views about how policy ought to be made in the National Health Service and in the public domain generally. There are those who believe that policy ought to be based on rational analysis: that decisions should be based on a dissection of the factsa tradition which has its roots in the activities of Chadwick and other 19th century health reformers. ${ }^{1}$ And there are those who believe that policy will, inevitably if regrettably, be shaped by the prejudices and interests of those involved: that decisions will reflect the political balance of power.

In this argument the report of the Resource Allocation Working Party ${ }^{2}$ is likely to be something of a test case. If intellectual analysis could solve the problems of the NHS then this document ought to receive an unreserved welcome. The logic behind its recommendations-that the distribution of resources to the regions ought to reflect not the legacy of history but the contemporary needs of their populations-is irresistible, while the methods used in calculating the appropriate allocations are elegantly and compellingly devised.

\section{New formula for allocation}

In contrast to the Working Party's interim report, ${ }^{3}$ the latest document is no longer open to the criticism that it proposes to redistribute resources to regions-like East Anglia-which may be below average in spending per head but are above average in terms of the health of the population concerned. The proposed new formula for allocating resources takes into account not only the composition of the population but also indicators of its state of health: and while there may be scope for detailed argument about the weight given to these indicators, standardised mortality ratios for particular conditions, it is unlikely that any resulting modifications would make much difference to the relative position of the different regions. Thus, while East Anglia's deficit has been cut, Mersey moves in the opposite direction: including SMRs in the calculation has reduced its surplus relative to the other regions. And Oxford joins the four Thames regions in being designated as a region with more than its share of resources. Indeed, the four metropolitan regions would remain at the top of this particular league table even if the working party had been more generous in its treatment of teaching hospital costs. ${ }^{4}$ This factor accentuated but does not account for their position.

Unfortunately, intellectual logic and political calculation are unlikely to point in the same direction when it comes to implementing the recommendations of the working party. In the past, when sustained economic growth seemed an attainable vision, it was possible to assume that progress towards a more equitable redistribution of resources could be achieved through a policy of differential growth. In other words, given the expectation of a steady growth in the total budget of the NHS it was reasonable to plan on the basis that everyone could be better off but that some would be better off than others-with the allocations to the deficit regions increasing at a faster rate than those to the surplus regions. But in Britain's current economic situation such a strategy no longer looks feasible. Given the constraints on public expenditure generally, it will be a minor miracle if the Government manages to sustain even its $2 \%$ a year growth target for revenue spending on health. Significantly, perhaps, the working party-in discussing future options-includes a scenario for negative growth, while its interim report considered only methods of distribution an increasing budget.

If there is to be any redistribution at all, in this situation it follows that this can only be achieved by cutting the allocation of the surplus regions. The working party does not commit itself to any precise recommendation as to the rate at which such a redistributive exercise should be carried out. It does, however, suggest that given a zero growth situation for the NHS consideration should be given to the possibility of cutting the allocations by more than $1^{\circ}$ and that a situation of overall negative growth might indicate cuts of up to $2 \frac{1}{2} \%$ for the best-off regions.

\section{Prospect serious}

The prospect is perhaps even more serious than these figures might indicate. The working party recommends that the distribution of resources to area health authorities should follow the same basic logic as that proposed for the RHAs. And, since the distribution of resources among AHAs is even more uneven than among the regions, ${ }^{5}$ it follows that the impact of any policy designed to bring about equity in a situation of overall stringency would require an even more drastic cutback in spending in the better-off areas.

Compounding the problem of implementing anything remotely resembling the working party's recommendation is another factor. The Government is committed not only to the principle of a more equitable geographical distribution of resources but also to a new set of priorities as between the different sectors of the NHS. ${ }^{6}$ For instance, it is proposing that expenditure on services for the elderly should rise by $3^{\circ}$ a year, and that on the mentally handicapped by $2 \cdot 8 \%$. To achieve anything like those targets in those AHAs whose overall allocation of resources is either to be frozen or cut would therefore imply a massive reduction in acute services.

The price of achieving geographical equity in the present situation is therefore the introduction of a large scale programme of hospital closures and manpower redundancy. If the Secretary of State, Mr David Ennals, accepts the working party's recommendations he is also accepting a battle with the trade unions and the professions concerned which will make Mrs Castle's reign look like an era of idyllic peace.

But why should any Secretary of State risk such a collision in pursuit of an abstract principle? There is in any such exercise an imbalance between the political costs and benefits. Closing down a hospital and sacking people has a high degree of political visibility. It is, as recent experience has shown, liable to provoke strikes and demonstrations. But making a marginal addition to someone's budget-taking on the odd extra doctor or nurse-is hardly calculated to hit the headlines, even though it may improve the quality of the local health service.

\section{Positive investment in change?}

Assuming that it is desirable to bring about a redistribution of resources-both geographically and between sectors-much may therefore depend on whether the Secretary of State is prepared to make a positive investment in change. That is, there seems to be a persuasive case for setting aside a specified proportion of the NHS's budget designed to make disruption acceptable. This might be cheap at the price: the frictional costs of introducing change-protracted negotiations, run-down institutions, declining morale -are not necessarily negligible simply because they remain unquantifiable.

At present, those working in the NHS threatened by change have-for the most part -no incentive to do anything except to resist it. This is as true of consultants as of hospital porters, and it is particularly true at a time of high unemployment when there are few alternative sources of work. If the Government's policy of redistributing resources aim is to be taken seriously it follows that a necessary first step is to create conditions designed to encourage the acceptance of change, whether by retraining programmes, compensation payments, or larger grants for people who have to move to a different part of the country. Redistribution is about lost jobs and shattered expectations, and no policy which fails to take account of this is likely to succeed-or, indeed, to be implemented by a Secretary of State who, naturally enough, will want to avoid cutting his own political throat.

There is a further consideration which should help to shape the implementation of the working party's recommendations. This is that redistributing financial resources cannot be (Concluded on p 895) 
prepared to accede to this then the profession should ask that the new arrangements should not be implemented so far as doctors were concerned and that there should be consultations on the part which doctors were to play in the procedure. Should these two requests be rejected then the profession might have to be advised as to how far doctors should or should not participate.

Mr Grabham's view was endorsed by the other organisations represented on the subcommittee, and subsequently by the Joint Consultants Committee. The CCHMS also supported the subcommittee's comments and approved a resolution from North-west RCHMS rejecting the draft complaints procedure and asking the CCHMS to resist by all means attempts by the DHSS to impose unilaterally a procedure which changed the terms and conditions of service and sought to interfere with clinical responsibility.

\section{Distinction awards}

The Negotiating Subcommittee had recommended that the following proposals should be submitted to the DHSS and the committee agreed: lists of the names of award holders should be held by each employing authority and be available at district level through the chairman of the medical executive committee, or the medical equivalent, and that information from those lists should be available confidentially to any member of the profession in the country; any member of the profession obtaining such information should be required to give an undertaking that it would not be divulged to any person outside the profession.

\section{CCHMS elections}

Chairman: Mr A H Grabham; first deputy chairman: $\mathrm{Mr} \mathrm{D}$ E Bolt; second deputy chairman: Dr E B Lewis.

\section{Executive Subcommittee}

The following were appointed: $\mathrm{Mr} \mathrm{D} \mathrm{E}$ Bolt (ex officio), Dr M Burrows, Mr R Myles Gibson, Mr R K Greenwood, $\mathrm{Mr}$ A $\mathrm{H}$ Grabham (ex officio), $\mathrm{Mr}$ T $M$ Hennebry, Mr J Kyle, Dr E B Lewis (chairman), Professor I Rannie, Mr R H B Mills (Welsh CHMS), Mr W Drummond (Scottish CHMS), and Dr G B S Roberts (Scottish CHMS).

\section{Negotiating Subcommittee}

The following were appointed: $\mathrm{Dr} \mathrm{W} \mathrm{J}$ Appleyard, Mr D E Bolt (chairman), Dr J M Cundy, Mr A H Grabham (ex officio), Mr T M Hennebry, Dr E R S Hooper, Dr E B Lewis, Professor I Rannie, Mr A Rhodes, Mr A P J Ross, Mr W Drummond (Scottish CHMS), and Dr G B S Roberts (Scottish CHMS).

The following committees are also represented: JCC, Compensation and Superannuation Committee, Full-time Medical Teachers and Research Workers Committee, Central Committee for Hospital Dental Services, N Ireland CHMS, and Central Committee for Community Medicine (observer).

\section{Consultant contract}

Mr D E Bolt referred to the discussion paper which the Negotiating Subcommittee had prepared on the consultant contract (11 September, $p$ 655). The aim, he said, had been to write a contract which offered advantages to consultants in almost any specialty. It was negotiable but would need the backing of a united profession in order to achieve it. $\mathrm{He}$ hoped that discussions would take place with the DHSS early in 1977.

Dr J M Cundy was concerned about how a sessional contract would work out in practice. He urged that the contract should be as flexible as possible so that it recognised work load and he suggested that sessions for call should be directly related to the amount of time that a person had on call.

The committee agreed that the paper should be debated as widely as possible and to ask regions for comments by the end of October.

\section{Central Manpower Committee: reform proposed}

Professor Ian Rannie presented the report of a working party which had reviewed the constitution and functioning of the Central Manpower Committee. The CCHMS accepted the working party's proposals and agreed that they should be sent to the Joint Consultants Committee on 19 October.

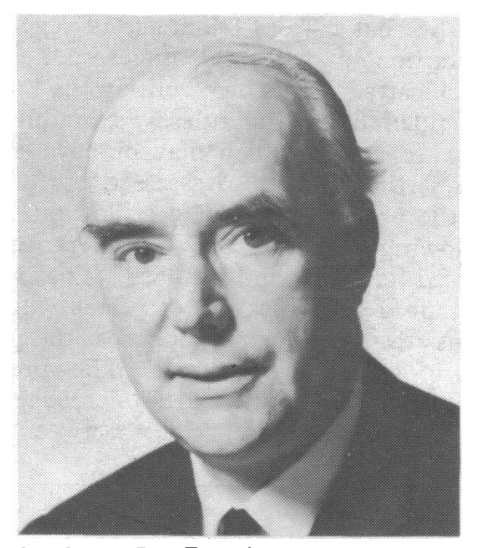

Professor Ian Rannie

The main problem had been how to secure the representation on the clinical side of each regional manpower committee and of all the royal colleges and faculties, while at the same time enabling the CMC to continue as a viable body. It was decided to augment the clinical side to ensure proper representation and to appoint an executive committee to meet DHSS representatives. The full clinical side would meet two or three times a year, the executive committee more frequently. The working party had envisaged that the subcommittees appointed by the CMC would continue as at present and that the executive committee would be empowered to communicate directly with the JCC, the CCHMS, and regional manpower committees.

The royal colleges and the faculties would determine how they were to be represented on the executive committee, with the seven representatives from the CCHMS selected from committee members from England and Wales with voting rights. The remaining eight additional seats on the full clinical side would be filled by the RCHMS for those regions which do not have a representative on the executive committee being invited to nominate a member who serves on the RMC. This should ensure that there was a member from each of the 14 regions in England and Wales on the full clinical side. The working party also proposed that the members appointed directly by the CCHMS should be co-opted to the appropriate RMC if they were not already members. Elections would be annual.

\section{Reconstituted CMC}

\section{Full clinical side}

$\begin{array}{lr}\text { Nominator } & \text { Members } \\ \text { Royal colleges and faculties } & 7 \\ \text { CCHMS } & 15 \\ \text { HJSC } & 3 \\ \text { CCHDS } & 1\end{array}$

Council for Postgraduate Medical

Education

General practitioners:

BMA

RCGP

\section{Executive committee}

Royal colleges and faculties
CCHMS
HJSC
CCHDS

CCHDS

\section{The politics of redistribution (continued)}

seen as an end in itself. The aim of such a policy is not to achieve equity in spending per head but in the delivery of medical care: to bring about, in the words of the report, "equal opportunity of access to health care for people at equal risk." But, as everyone knows, two health authorities with equal resources may be very unequal in their ability to spend the money in such a way as to meet the local community's needs effectively and efficiently. This would suggest that the Department of Health and Social Security should give urgent priority to devising and introducing indicators of access - of the kind being developed in the United States ${ }^{7}$-which would measure the extent to which the redistribution of money is also leading to the redistribution of care for the populations concerned.

\section{References}

1 Klein, R, Policy Analysis, 1976, 2, 459. Sharing Resources for Health in England, DHSS.

London, HMSO, 1976.
Allocations to Regions in 1976-7. First Interim Report of Resource Allocation Working Party, DHSS. London, HMSO, 1975

S Ritish Medical fournal, 1976, 2, 779. Priorities for Health and Personal Social Services in England, DHSS. London, HMSO, 1976.

Aday, L A, and Andersen, R, Health Services Research, 1976, 9, 208.

Centre for Studies in Social Policy, London 